\title{
A Frame Element Model for the Nonlinear Analysis of FRP-Strengthened Masonry Panels Subjected to In-Plane Loads
}

\author{
Ernesto Grande, Maura Imbimbo, Alessandro Rasulo, and Elio Sacco \\ Department of Civil and Mechanical Engineering (DICeM), University of Cassino and Southern Lazio, \\ Via G. Di Biasio 43, 0043 Cassino, Italy \\ Correspondence should be addressed to Ernesto Grande; e.grande@unicas.it
}

Received 20 May 2013; Accepted 1 August 2013

Academic Editor: Vladimir Tsukruk

Copyright (c) 2013 Ernesto Grande et al. This is an open access article distributed under the Creative Commons Attribution License, which permits unrestricted use, distribution, and reproduction in any medium, provided the original work is properly cited.

A frame element model for evaluating the nonlinear response of unstrengthened and FRP-strengthened masonry panels subjected to in-plane vertical and lateral loads is presented. The proposed model, based on some assumptions concerning the constitutive behaviour of masonry and FRP material, considers the panel discretized in frame elements with geometrical and mechanical properties derived on the basis of the different states characterizing the sectional behaviour. The reliability of the proposed model is assessed by considering some experimental cases deduced from the literature.

\section{Introduction}

Masonry constructions certainly constitute an important part of the existing buildings in several countries and, in many cases, of their cultural heritage [1]. Past and recent seismic events $[2,3]$ have pointed out a significant level of vulnerability of such constructions and have posed the necessity to develop adequate and effective retrofit and strengthening systems able to improve their seismic resistance.

In the last decades, strengthening techniques based on the use of fiber-reinforced polymers (FRPs) materials have been proposed. Among these, one of the most commonly used technique is represented by FRP strips which can be externally applied on both the concrete masonry structures [4-6].

The literature related to FRP-strengthening systems has clearly demonstrated the capacity of such systems to improve the structural performances of masonry structures [7-9]. Some of the major drawbacks in modeling FRP-strengthened structures are certainly related to the interaction mechanism between masonry and FRPs at their interface layer. Many studies have specifically investigated the bond response of FRP applied on masonry supports [10-12], and some of them have provided theoretical laws for modeling such behavior and developing numerical models [13-20].
On the other side, some studies have focused on the definition of reliable numerical tools to be used in the assessment of the performances of the strengthened constructions and in the design of the strengthening systems themselves. Among these are the approaches developed within the finite element formulation framework. In particular, many authors have proposed modeling approaches based on the use of nonlinear interface elements interposed between the support and the FRP strengthening and characterized by constitutive laws derived by tests or by theoretical considerations $[21,22]$. Other approaches have considered homogenization procedures for including the behavior of the FRP/support interface into the model of the FRP-reinforcement or, directly, in the masonry model [23-25]. In this context, the approaches based on the schematization of masonry elements strengthened with FRPs by using frame elements are of particular interest since they are in accordance with the equivalent frame approach which is useful in the design and implemented in many commercial computer codes for the structural analysis of masonry structures [26].

The model herein proposed for the nonlinear analysis of masonry panels strengthened with FRPs belongs to the equivalent frame approach and aims at providing a simple and effective tool to be used in the phase of assessment of masonry structures and, also, in the preliminary design of the FRP-strengthening systems. 


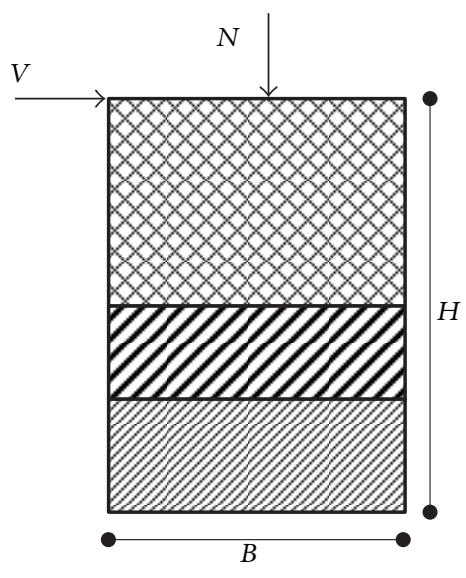

(a)

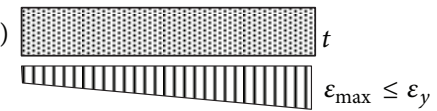

(b)

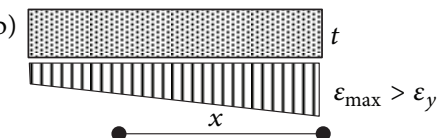

(c)

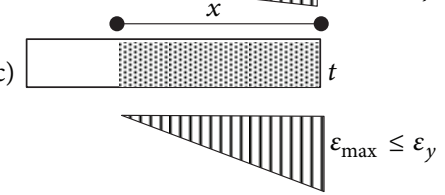

(d)

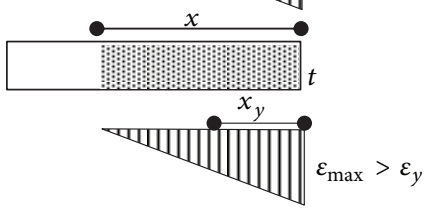

FIGURE 1: States characterizing the behavior of the cross-sections composing the panel.

\section{The Proposed Model}

The proposed model is based on simple considerations concerning the structural response of masonry panels subjected to in-plane loads.

Consider the masonry panel shown in Figure 1, subjected to a constant vertical load $N$ acting along the central axis of the panel and to a horizontal force $V$ applied at the top of the panel. By increasing the force $V$, the stress-strain state characterizing the behavior of the panel cross-sections varies continuously along its height. In particular, assuming for the masonry material a no-tensile behavior with an elastic perfectly-plastic response in compression, the following states can be identified (Figure 1):

(a) the whole section is in compression, and the material behaves elastically $\left(\varepsilon_{\max } \leq \varepsilon_{y}\right)$;

(b) the whole section is in compression, and the material behaves plastically $\left(\varepsilon_{\max }>\varepsilon_{y}\right)$;

(c) only a portion $x$ of the section is in compression, and here the material behaves elastically $\left(\varepsilon_{\max } \leq \varepsilon_{y}\right)$;

(d) only a portion $x$ of the section is in compression, and here the material behaves plastically $\left(\varepsilon_{\max }>\varepsilon_{y}\right)$;

with $\varepsilon_{\max }$ being the maximum value of the strain in compression and $\varepsilon_{y}$ the strain value corresponding to the elastic limit of the masonry material.

At each value of the force $V$, the masonry panel can be considered as composed, along its height, of different homogenous zones with each one characterized by one of the above states. The number of these zones and their extension along the panel height depend on several parameters such as the masonry properties, the value of the applied loads, and the geometry of the panel.

The model proposed herein consists of schematizing the panel as an assemblage of elements, with flexure and shear deformability, representing the homogenous zones. An example of the model is reported in Figure 2. In particular, Figure 2(a) shows the case of a single element while Figures 2(b) and 2(c) show the case of more elements, one element at the top with all the sections fully compressed and the other elements where the sections are not entirely in compression.

The properties of each element-length and resisting cross-section-are defined by the properties of the corresponding homogenous zone. In particular, the cross-section area and the moment of inertia of each element are assumed to be constant and, for each step of load, are equal to the average value of the cross-section area and the moment of inertia characterizing the resisting sections located at the ends of the homogenous zone. Each element is, then, described by a stiffness matrix derived by taking into account also the shear deformability introduced through the terms $s$ and $e$ and given by

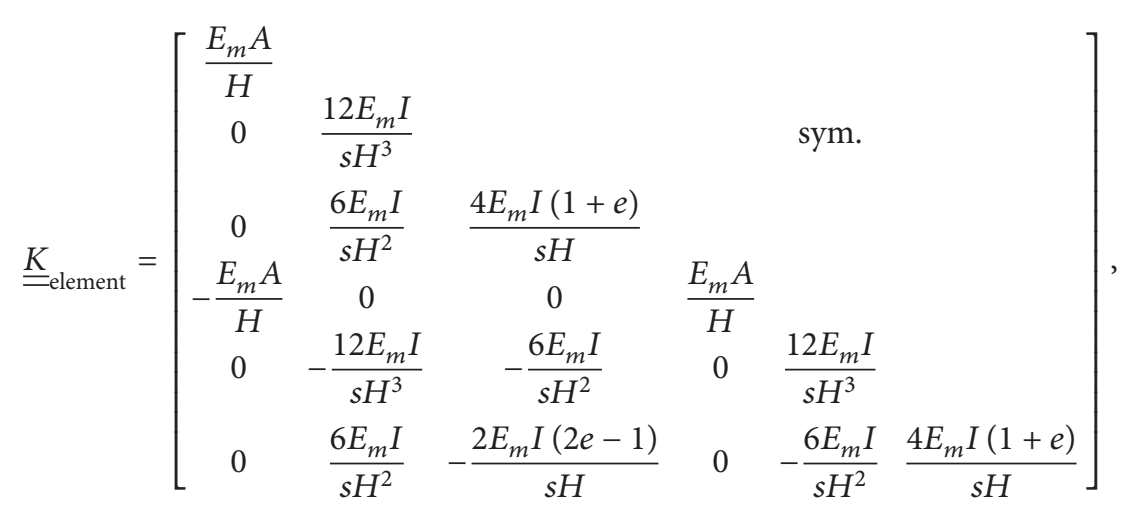


where $H$ is length of the considered element, $A$ average value of the cross-section area of the resisting sections located at the ends of the element, $I$ average value of the moment of inertia of the resisting sections, $E_{m}$ Young's modulus of masonry, $G_{m}$ shear modulus of masonry; $e=3 E_{m} I \chi / G_{m} A H^{2}$ with $\chi$ the shear factor of the resisting section and $s=1+4 e$.

Indeed, in the context of the equivalent frame modeling approach, the shear deformability plays a crucial role in deriving the seismic response of masonry structures since the capacity curve obtained through a pushover analysis is devoted to furnish both the peak load (resistance) of the structure and the failure mechanism affecting piers and spandrels, also a measure of the ultimate displacement capacity necessary for evaluating the global ductility of the structure.

Finally, the stiffness matrix of the panel $\underline{\underline{K}}_{\text {panel }}$ is obtained by assembling the stiffness matrices of each element.

The model defined for the case of unstrengthened panels is, then, extended to the case of FRP-strengthened panels. In this case, the following additional hypotheses have been introduced:

(i) a no-compression behavior for the FRP-strengthening system with a linear-elastic behavior in tension until its failure or the decohesion occurs;

(ii) absence of slip phenomena between masonry and FRP-strengthening.

Considering the above hypotheses, it is evident that additional states, besides those (a) to (d) previously defined, would occur when the strengthening system is activated. Consequently, in these cases additional homogeneous zones will characterize the behavior of the FRP-strengthened panels.

The proposed model is applied to evaluate the nonlinear response of the panel in terms of its capacity curve. The procedure is articulated into two phases: the first phase aimed at analyzing the stress-strain state, and the second phase is devoted to evaluate the lateral displacement exhibited by the panel during the increments of the lateral force $V$.

The equations characterizing the first phase are equilibrium and constitutive equations and will be reported in detail in the following sections for unstrengthened and strengthened panels. These equations allow evaluating the stress-strain state at the base section of the panel, where deformations assume the maximum values, and at the sections where a change of the states occurs.

In the second phase, for each value of the applied force $V$ it is possible to derive the corresponding value of the lateral displacement $D$ at the top of the panel.

The capacity curve of the panel, that is, the curve in terms of the applied force $V$ versus the top displacement $D$, can be finally derived. This curve is representative of the global response of the panel and takes into account the process of formation of the homogenous zones characterizing the structural response of the panel.

The procedure is analyzed in detail in the following sections for unstrengthened and strengthened panels.
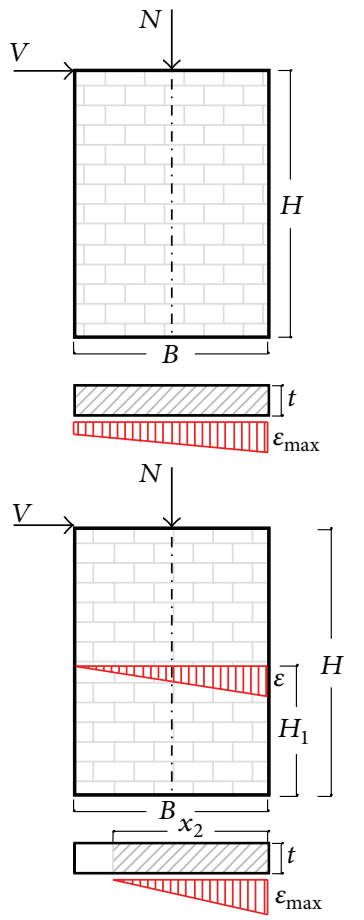

(a)

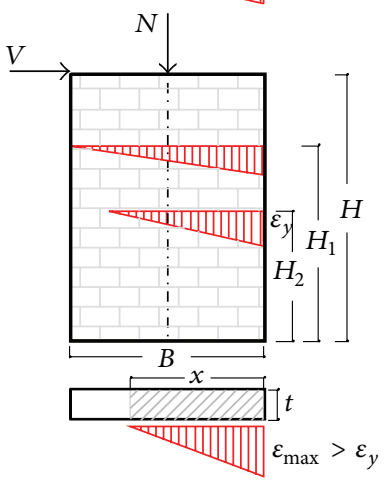

(b)

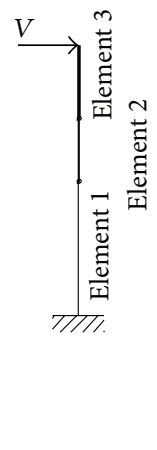

(c)

FIGURE 2: Unstrengthened panels: schemes of assemblage of frame elements.

2.1. Unstrengthened Panels. With reference to the panel shown in Figure 2, subjected to a vertical force $N$, constant and acting along the central axis of the panel, and to a horizontal force $V$ monotonically increasing, the position of the neutral axis, indicated by $x$, defines two possible states at the base section of the panel:

(a) the whole section is in compression $(x>B$, Figure 2(a));

(b) only a portion of the section is in compression $(x<B$, Figures 2(b) and 2(c)).

In the first case, the panel is modeled through a single element (Figure 2(a)) while, in the second case, the panel is modeled by two or more elements (Figures 2(b) and 2(c)), one representing the portion of the panel where the sections are fully compressed and the others representating the parts where the sections are not fully compressed $(x<B)$. For both cases, the attained maximum strain $\varepsilon_{\max }$ activated 


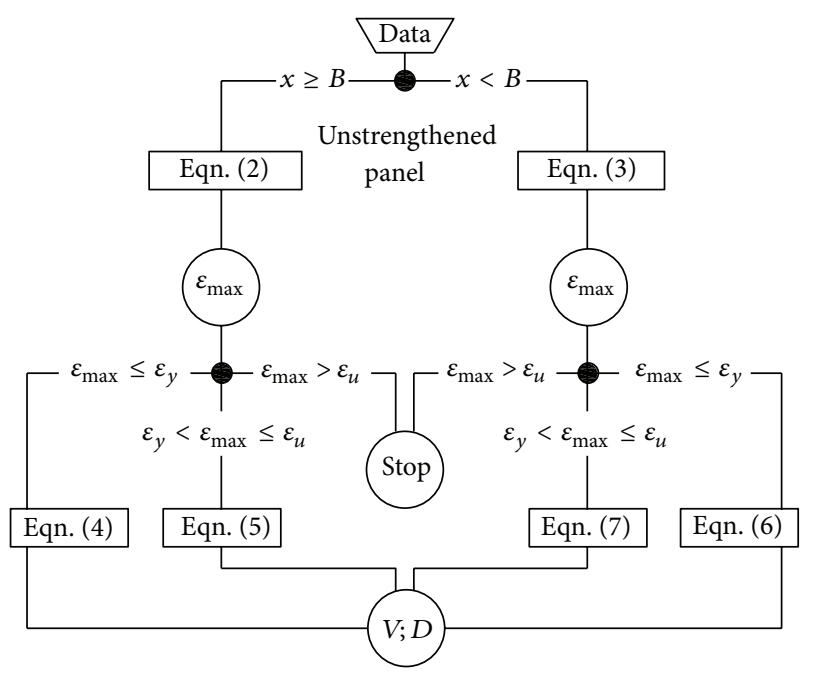

FIGURE 3: Flowchart of the procedure for unstrengthened panels.

in the sections cannot exceed the ultimate value $\varepsilon_{u}$ which indicates the failure condition for the panel. In both cases, the maximum strain can assume values less or greater than the yield strain $\varepsilon_{y}$; when $\varepsilon_{\max }$ exceeds $\varepsilon_{y}$, three elements are necessary for schematizing the panel (Figure 2(c)).

The set of equations used for deriving the stress-strain state of the panel sections and the selected procedure for carrying out the capacity curve have been implemented in MATLAB [28]. The flowchart shown in Figure 3 schematically represents the main steps of the procedure for the case of unstrengthened panels. In particular, considering different positions of the neutral axis for the base section of the panel, the corresponding horizontal force $V$ and displacement $D$ at the top of the panel are derived by considering the following five steps of analysis.

(1) Assign the position of the neutral axis, $x$, which could be external or internal to the section ( $x \geq B$ or $x<B$, resp.).

(2) Evaluate the maximum strain in the masonry, $\varepsilon_{\max }$, through the following set of equations.

Case of $x \geq B$. If $\varepsilon_{\max } \leq \varepsilon_{y}$,

$$
\begin{gathered}
\varepsilon_{\max }=\frac{2 N}{E_{m} \cdot B \cdot t \cdot(1+((x-B) / x))}, \\
\varepsilon_{\min }=\varepsilon_{\max } \cdot \frac{x-b}{x},
\end{gathered}
$$

if $\varepsilon_{y}<\varepsilon_{\max } \leq \varepsilon_{u}$,

$$
\frac{\varepsilon_{\max }}{x}=\frac{\varepsilon_{\min }}{x-B}=\frac{\varepsilon_{y}}{x_{s}}
$$

$$
f_{m k}\left(x-x_{s}\right) t+\frac{f_{m k}+E_{m} \cdot \varepsilon_{\min }}{2} t \cdot\left(2 B-2 x+x_{s}\right)=N .
$$

Case of $x<B$. If $\varepsilon_{\max } \leq \varepsilon_{y}$,

$$
\varepsilon_{\max }=\frac{2 N}{E_{m} \cdot x \cdot t},
$$

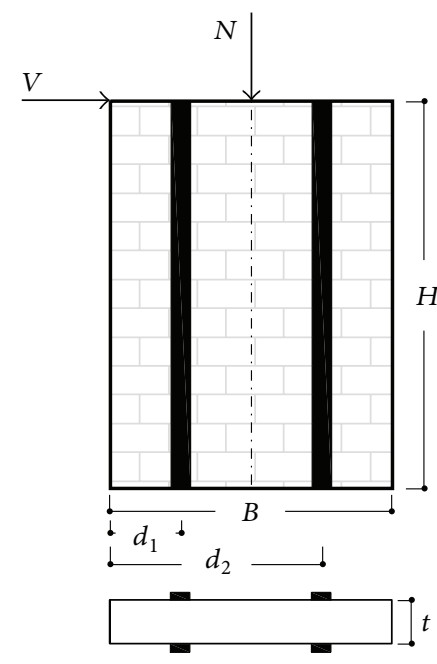

FIGURE 4: Strengthening configuration of the panel.

$$
\begin{aligned}
& \text { if } \varepsilon_{y}<\varepsilon_{\max } \leq \varepsilon_{u}, \\
& \varepsilon_{\max }=\frac{(1 / 2) f_{m k} \cdot t \cdot x \cdot \varepsilon_{y}}{\left(f_{m k} \cdot t \cdot x-N\right)},
\end{aligned}
$$

where $f_{m k}$ is the masonry strength and $x_{s}$ indicates the fiber where the elastic limit strain is attained.

(3) Check the derived value of $\varepsilon_{\max }$ in order to establish the number of elements composing the panel.

(4) Evaluate the force $V$ corresponding to the assigned position of the neutral axis through the following set of equations which are dependent on the position of the neutral axis, the value of the maximum strain, and the characteristics of the elements composing the panel (number of elements, length and properties of the cross-section of each element).

Case of $x \geq B$. If $\varepsilon_{\max } \leq \varepsilon_{y}$,

$$
V=\frac{\left[(1 / 2) E_{m}\left(\varepsilon_{\max }-\varepsilon_{\min }\right) \cdot t\left(B^{2} / 6\right)\right]}{H},
$$

if $\varepsilon_{y}<\varepsilon_{\max } \leq \varepsilon_{u}$,

$$
\begin{gathered}
V=\frac{Y_{1}+Y_{2}}{H}, \\
Y_{1}=\left[\left(f_{m k}+E_{m} \varepsilon_{\min }\right) t\left(x-x_{s}\right)\left(\frac{B-x+x_{s}}{2}\right)\right], \\
Y_{2}=\left[\frac{1}{2}\left(f_{m k}-E_{m} \varepsilon_{\min }\right) t\left(2 B-2 x+x_{s}\right)\left(\frac{2 x-B+x_{s}}{6}\right)\right] .
\end{gathered}
$$

Case of $x<B$. If $\varepsilon_{\max } \leq \varepsilon_{y}$,

$$
\begin{gathered}
V=\frac{\left[(1 / 2) E_{m} \varepsilon_{\max } x \cdot t(B / 2-x / 3)\right]}{H}, \\
H_{1}=H-\frac{N \cdot B}{6 V},
\end{gathered}
$$




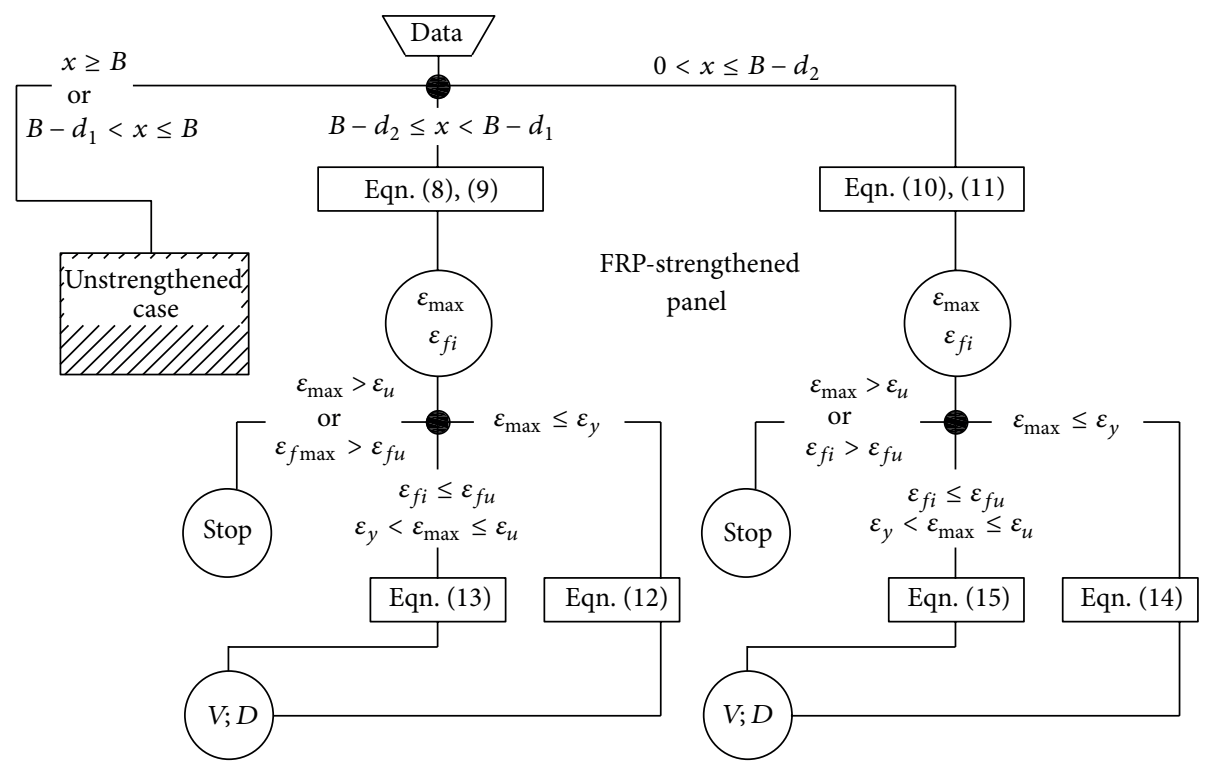

FIGURE 5: Flowchart of the procedure for FRP-strengthened panels.

if $\varepsilon_{y}<\varepsilon_{\max } \leq \varepsilon_{u}$,

$$
\begin{gathered}
V=\frac{\left[(1 / 2) f_{m k} x_{s} \cdot t\left(B / 2+2 x_{s} / 3-x\right)\right]}{H} \\
+\frac{\left[f_{m k}\left(x-x_{s}\right) \cdot t\left(\left(B-x+x_{s}\right) / 2\right)\right]}{H} . \\
H_{1}=H-\frac{N \cdot B}{6 V}, \\
H_{2}=H-\frac{N}{V}\left(\frac{B}{2}-\frac{2 N}{3 f_{m k} \cdot t}\right) .
\end{gathered}
$$

(5) Evaluate the top displacement $D$ of the panel corresponding to the force $V$ calculated at the previous step by using the stiffness matrix of the panel $\underline{K}_{\text {panel }}$.

The procedure is then repeated starting from a new position of the neutral axis, and it continues until the ultimate value of the strain is attained. Then the capacity curve $V$ - $D$ of the panel is derived.

The capacity curve provides two pieces of information, the first related to the maximum horizontal force sustained by the panel and the second related to its ductility which is defined as the ratio between the ultimate displacement and the displacement corresponding to the attainment of the masonry yield strain.

It is important to emphasize that the different phases characterizing the behavior of the panel and, consequently, its schematization through frame elements require to operate in terms of increments of load since the nonlinearity of the response leads to a variation of the stiffness matrix of the model at each load increment.

2.2. FRP-Strengthened Panels. The model proposed for the case of the unstrengthened panels has been extended to the case of masonry panels strengthened with FRP strips bonded on the external surface (Figure 4). The equations used for deriving the capacity curve are those carried out for the case of the unstrengthened panels with additional equations referring to the sections where the strengthening is activated.

In Figure 5 the flowchart schematizing the steps of the procedure for the case of FRP-strengthened panels is reported. It is possible to observe that the procedure differs with respect to the one developed for the unstrengthened panels only when the position of the neutral axis leads to the activation of the FRP strips. In Figures 6 and 7 the schemes of the strengthened panels used for deriving the equations are reported as follows.

(1) Assign the position $x$ of the neutral axis.

(2) Evaluate the maximum value of the strain in the masonry and the strengthening through the following set of equations.

Case of $B-d_{2} \leq x<B-d_{1}$. If $\varepsilon_{\max } \leq \varepsilon_{y}$,

$$
\begin{gathered}
\frac{\varepsilon_{\max }}{x}=\frac{\varepsilon_{f 1}}{B-d_{1}-x}, \\
\frac{1}{2} E_{m} \varepsilon_{\max } t \cdot x-E_{f} \varepsilon_{f 1} A_{f 1}=N,
\end{gathered}
$$

if $\varepsilon_{y}<\varepsilon_{\max } \leq \varepsilon_{u}$,

$$
\begin{gathered}
\frac{\varepsilon_{\max }}{x}=\frac{\varepsilon_{f 1}}{B-d_{1}-x}=\frac{\varepsilon_{y}}{x_{s}}, \\
\frac{1}{2} f_{m k} t \cdot x_{s}+f_{m k} t \cdot\left(x-x_{s}\right)-E_{f} \varepsilon_{f 1} A_{f 1}=N .
\end{gathered}
$$

Case of $0<x \leq B-d_{2}$. If $\varepsilon_{\max } \leq \varepsilon_{y}$,

$$
\begin{gathered}
\frac{\varepsilon_{\max }}{x}=\frac{\varepsilon_{f 1}}{B-d_{1}-x}=\frac{\varepsilon_{f 2}}{B-d_{2}-x}, \\
\frac{1}{2} \varepsilon_{\max } E_{m} t \cdot x-E_{f} \varepsilon_{f 1} A_{f 1}-E_{f} \varepsilon_{f 2} A_{f 2}=N,
\end{gathered}
$$




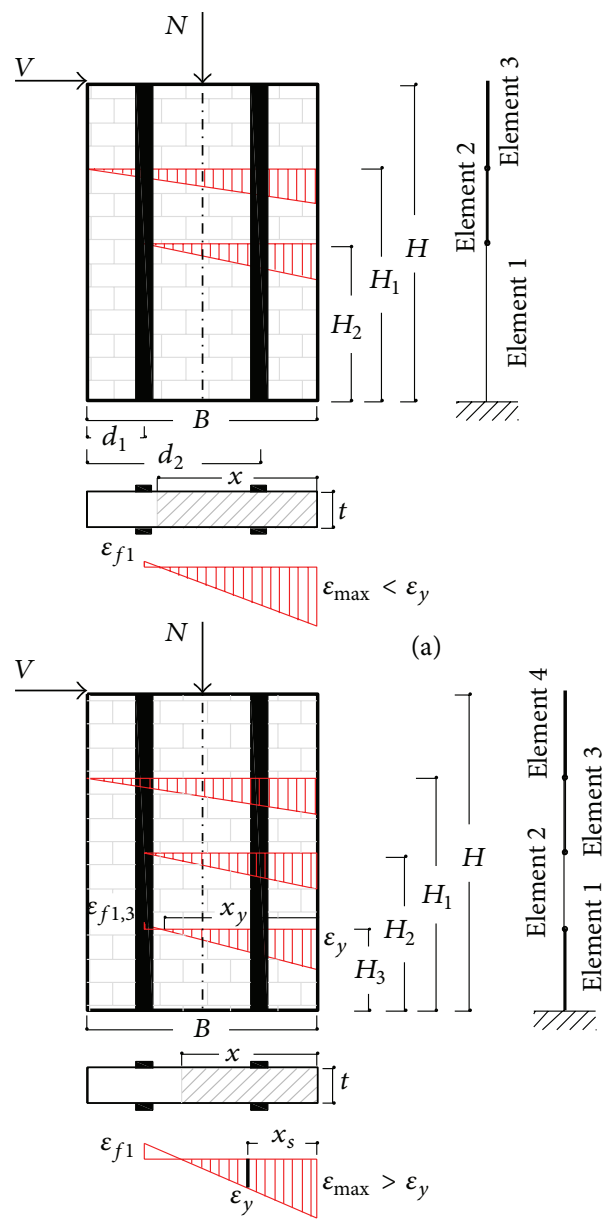

(b)

FIGURE 6: FRP-strengthened panels: schemes of assemblage of frame elements.

$$
\begin{aligned}
& \text { if } \varepsilon_{y}<\varepsilon_{\max } \leq \varepsilon_{u}, \\
& \qquad \frac{\varepsilon_{\max }}{x}=\frac{\varepsilon_{f 1}}{B-d_{1}-x}=\frac{\varepsilon_{f 2}}{B-d_{2}-x}, \\
& N=\frac{1}{2} f_{m k} t \cdot x_{s}+f_{m k} t \cdot\left(x-x_{s}\right)+E_{f} \varepsilon_{f 1} A_{f 1}+E_{f} \varepsilon_{f 2} A_{f 2},
\end{aligned}
$$

where $\varepsilon_{f 1}$ and $\varepsilon_{f 2}$ are the tensile strains of the FRP strips at the base of the panel and $A_{f 1}$ and $A_{f 2}$ are the corresponding cross-section areas.

(3) Check the evaluated maximum strain in the masonry and FRP derived from the previous set of equations. In particular, the attainment of the ultimate deformation either in masonry or in FRP leads to stopping the procedure.

(4) Evaluate the force $V$ by introducing a further set of equations.

Case of $B-d_{2} \leq x<B-d_{1}$. If $\varepsilon_{\max } \leq \varepsilon_{y}$,

$$
\begin{gathered}
V=\frac{(1 / 2) \varepsilon_{\max } \cdot E_{m} t \cdot x(B / 2-x / 3)}{H} \\
+\frac{E_{f 1} \varepsilon_{f} A_{f}\left(B / 2-d_{1}\right)}{H},
\end{gathered}
$$
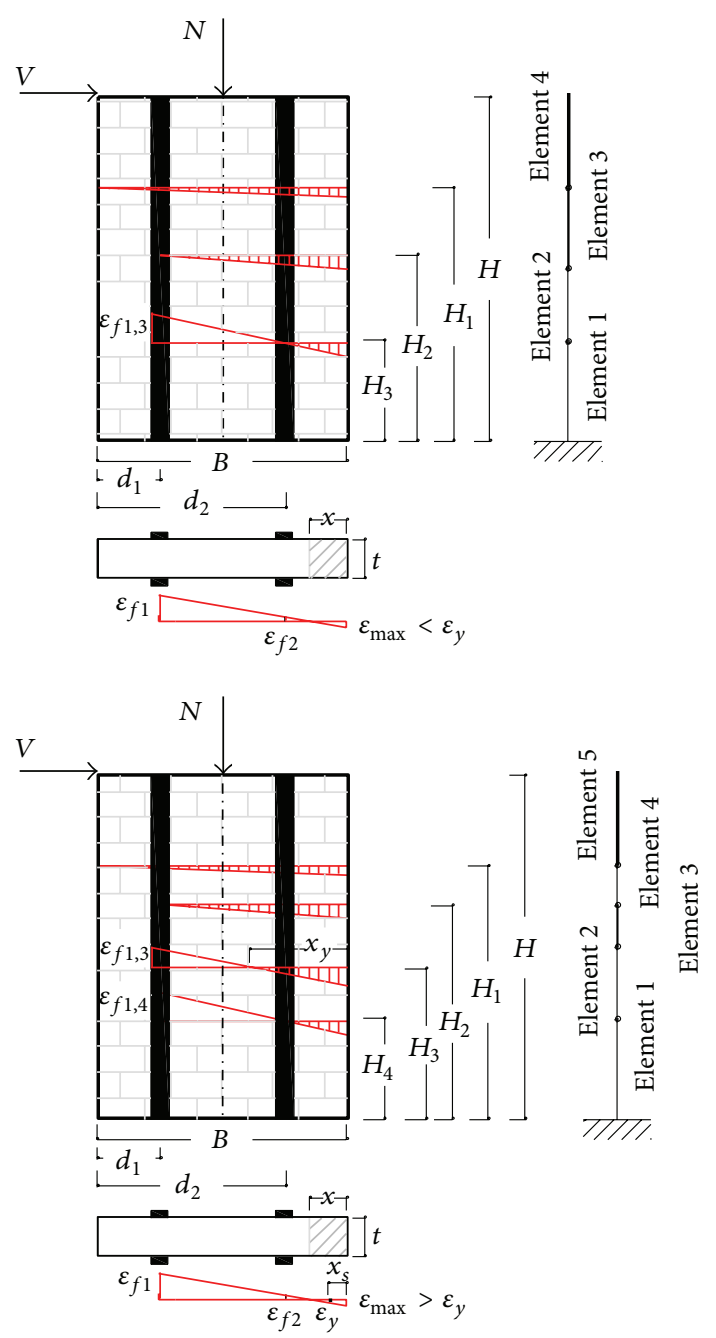

FIGURE 7: FRP-strengthened panels: schemes of assemblage of frame elements.

$$
\begin{aligned}
& H_{1}=H-\frac{N \cdot B}{6 \cdot V} \\
& H_{2}=H-N \cdot\left(\frac{B}{6}+\frac{d_{1}}{3}\right) \frac{1}{V},
\end{aligned}
$$

if $\varepsilon_{y} \leq \varepsilon_{\max } \leq \varepsilon_{u}$,

$$
\begin{aligned}
& V=\frac{Y_{1}+Y_{2}+Y_{3}}{H} \\
& Y_{1}=\frac{1}{2} f_{m k} t \cdot x_{s}\left[\frac{B}{2}-\left(x-x_{s}\right)-\frac{x_{s}}{3}\right], \\
& Y_{2}=f_{m k}\left(x-x_{s}\right) t \cdot\left(\frac{B}{2}-\frac{x-x_{s}}{2}\right), \\
& Y_{3}=\varepsilon_{f} \cdot E_{f} \cdot A_{f}\left(\frac{B}{2}-d_{1}\right) \\
& H_{1}=H-\frac{N \cdot B}{6 \cdot V}
\end{aligned}
$$




$$
\begin{aligned}
H_{2}= & H-N \cdot\left(\frac{B}{6}+\frac{d_{1}}{3}\right) \frac{1}{V}, \\
H_{3}= & H \\
& -\frac{(1 / 2) f_{m k} t \cdot x_{y}\left(B / 2-x_{y} / 3\right)}{V}, \\
& +\frac{+\varepsilon_{f 1,2} E_{f} A_{f 1}\left(B / 2-d_{1}\right)}{V}, \\
x_{y}= & \frac{N-\varepsilon_{f 1,3} E_{f} A_{f 1}}{(1 / 2) f_{m k} t} .
\end{aligned}
$$

Case of $0<x \leq B-d_{2}$. If $\varepsilon_{\max } \leq \varepsilon_{y}$,

$V=\frac{Y_{1}+Y_{2}+Y_{3}}{H}$

$Y_{1}=\frac{1}{2} \varepsilon_{\max } \cdot E_{m} t \cdot x\left(\frac{B}{2}-\frac{x}{3}\right)$

$Y_{2}=E_{f} \varepsilon_{f 1} A_{f 1}\left(\frac{B}{2}-d_{1}\right)$,

$Y_{3}=E_{f} \varepsilon_{f 2} A_{f 2}\left(\frac{B}{2}-d_{2}\right)$

$H_{1}=H-\frac{N \cdot B}{6 \cdot V}$

$H_{2}=H-N \cdot\left(\frac{B}{2}-\frac{B-d_{2}}{3}\right) \frac{1}{V}$

$H_{3}=H-\frac{(1 / 2) f_{m k} x_{y} t\left(B / 2-x_{y} / 3\right)+\varepsilon_{f 1,3} E_{f} A_{f}\left(B / 2-d_{1}\right)}{V}$

if $\varepsilon_{y} \leq \varepsilon_{\max } \leq \varepsilon_{u}$,

$$
\begin{aligned}
& V=\frac{Y_{1}+Y_{2}+Y_{3}+Y_{4}}{H}, \\
& Y_{1}=\frac{1}{2} f_{m k} t \cdot x_{s}\left(\frac{B}{2}-x+\frac{2 x_{s}}{3}\right), \\
& Y_{2}=f_{m k} t \cdot\left(x-x_{s}\right)\left(\frac{B}{2}-\frac{x-x_{s}}{2}\right), \\
& Y_{3}=E_{f} \varepsilon_{f 1} A_{f 1}\left(\frac{B}{2}-d_{1}\right), \\
& Y_{4}=E_{f} \varepsilon_{f 2} A f_{f 2}\left(\frac{B}{2}-d_{2}\right), \\
& H_{1}=H-\frac{N \cdot B}{6 \cdot V}, \\
& H_{2}=H-N \cdot\left(\frac{B}{6}+\frac{d_{1}}{3}\right) \frac{1}{V},
\end{aligned}
$$

$$
\begin{gathered}
H_{3}=H-\frac{(1 / 2) f_{m k} t x_{y}\left(B / 2-x_{y} / 3\right)}{V} \\
+\frac{\varepsilon_{f 1,3} A_{f 1} E_{f}\left(B / 2-d_{1}\right)}{V}, \\
H_{4}=H-\frac{Z_{1}+Z_{2}+Z_{3}}{V}, \\
Z_{1}=\frac{1}{2} f_{m k} t \cdot x_{s 4}\left(\frac{B}{2}-x_{4}+\frac{2 x_{s 4}}{3}\right), \\
Z_{2}=f_{m k} t \cdot\left(x_{4}-x_{s 4}\right)\left(\frac{B}{2}-\frac{x_{4}-x_{s 4}}{2}\right), \\
Z_{3}=E_{f} \varepsilon_{f 1,4} A_{f 1}\left(\frac{B}{2}-d_{1}\right) .
\end{gathered}
$$

(5) Evaluate the top displacement $D$ of the panel corresponding to the force $V$ calculated at the previous step by using the stiffness matrix of the panel $\underline{\underline{K}}_{\text {panel }}$. Then the capacity curve $V-D$ of the strengthened panel is derived. The capacity curve provides the maximum horizontal force sustained by the panel and its ductility defined as the ratio between the ultimate displacement, corresponding to either the masonry failure or the FRP failure/decohesion, and the displacement corresponding to the attainment of the masonry yield strain.

The process is then repeated starting from a new position of the neutral axis, and it continues until the ultimate value of the strain is attained.

\section{Numerical Applications}

The proposed model has been applied with reference to some cases of study deduced from the literature and for which the capacity curves were deduced experimentally.

The main characteristics of the analyzed panels are summarized in Table 1, and they refer to the following literature studies: Fantoni, 1981 [29], panels denoted by (a, b, and c); Giambanco et al. 1996 [30], panel denoted by panel (d); Giuffrè and Grimaldi, 1985 [31], panel denoted by panel (e); Callerio, 1998 [32], panel denoted by panel (f); Marcari, 2005 [27], panel denoted (g). The panels are characterized by different geometrical dimensions and mechanical properties of masonry, important for assessing the sensibility of the model.

The reliability of the proposed model is analyzed, for each unstrengthened and strengthened panel, by comparing the capacity curve obtained by the model itself with the experimental curve. Further results have been also derived from the numerical analyses in order to better investigate the structural response of the panels.

3.1. Unstrengthened Panels. The capacity curves $V$-D deduced by using the proposed model developed for the unstrengthened masonry panels have been compared with the experimental curve derived from the related studies [29-32]. The comparisons are reported in Figures $8(\mathrm{a})-8(\mathrm{f})$ where the experimental results are indicated by circular symbols and the numerical results by continuous lines. Figure 8 shows 


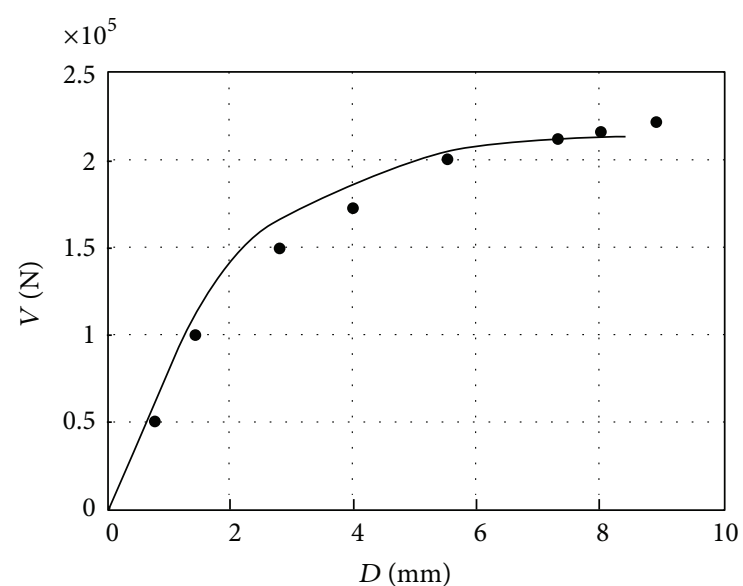

(a)

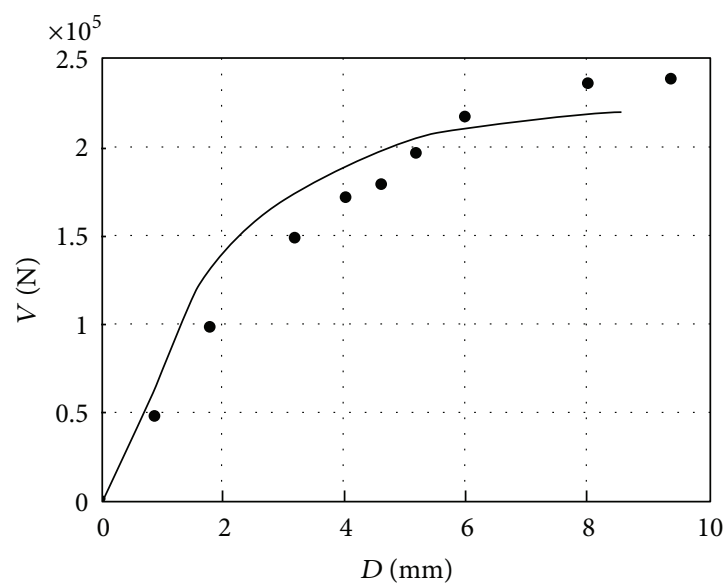

(c)

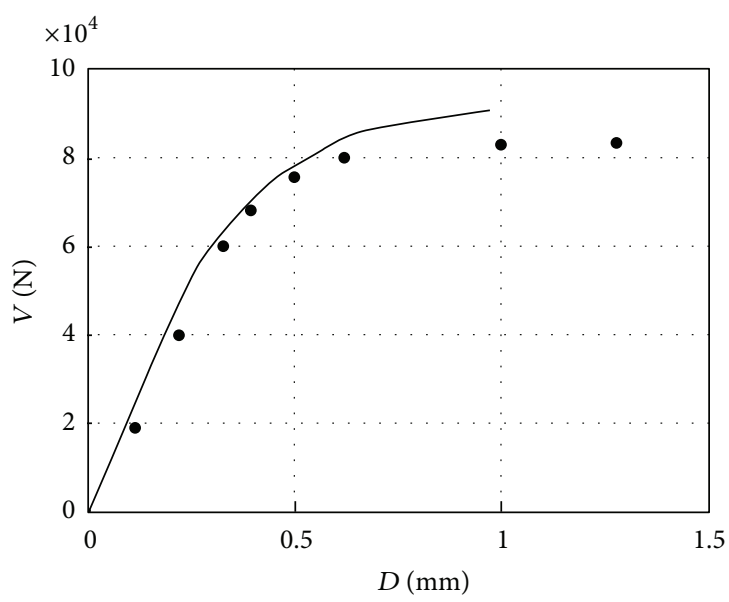

(e)

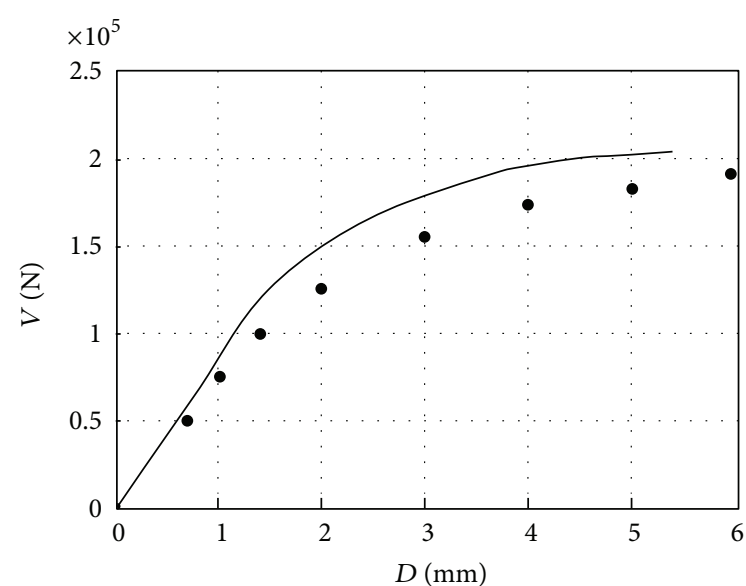

(b)

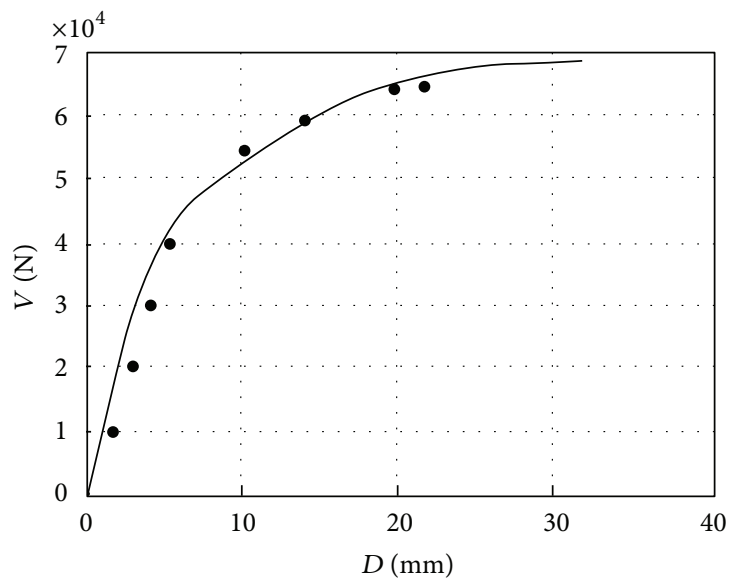

(d)

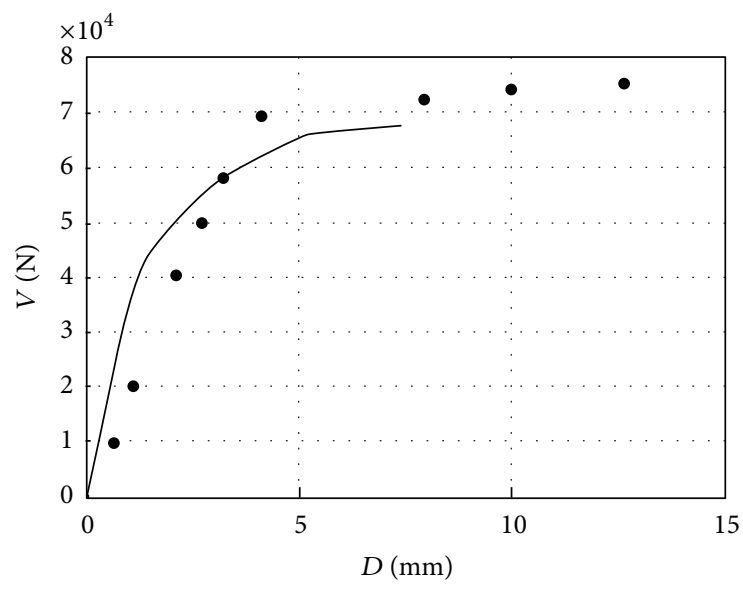

(f)

FIGURE 8: Comparisons between numerical and experimental capacity curves of unstrengthened panels.

a good agreement between the numerical and the experimental results in terms of the maximum load and, in many cases, in terms of ultimate displacement.

The proposed model is, then, applied to examine different aspects of the panels behavior. In Figure 9 the variation of the height $\mathrm{H}_{2}$, is analyzed representing the amplitude of the plastic zone of the panel where the maximum strain exceeds the yield strain value of the masonry, as a function of the position of the neutral axis at the base section. From the plots of Figure 9 it is possible to observe a similar behavior for 


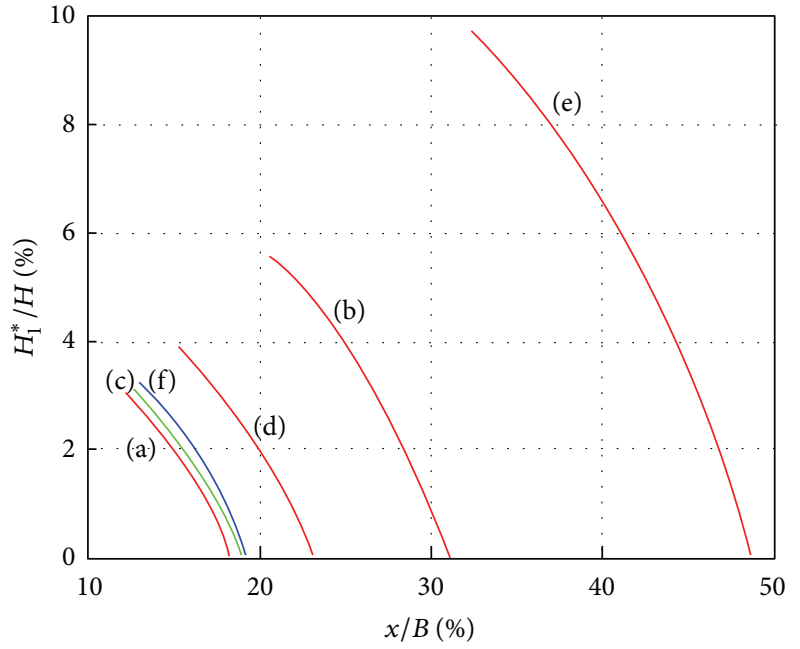

FIGURE 9: Variation of the dimensions of the plastic zone for the unstrengthened panels.
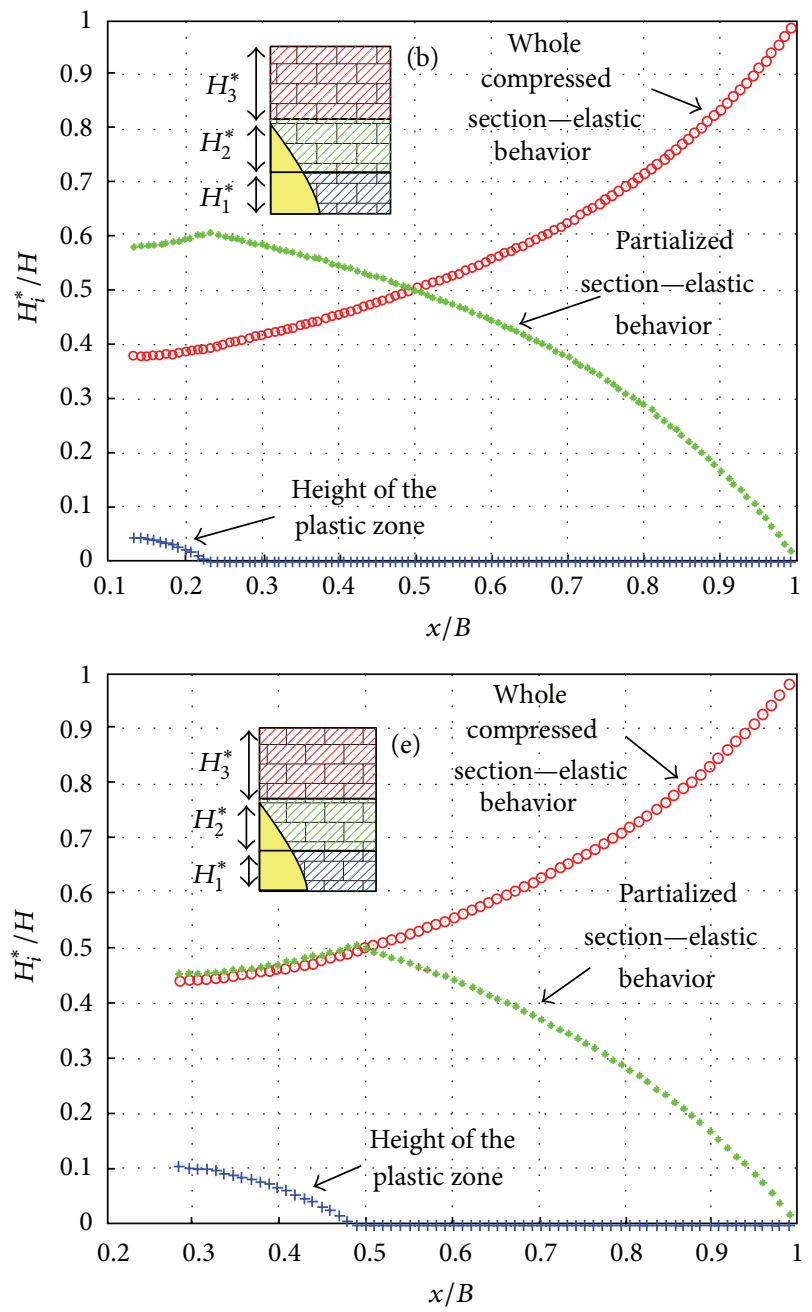

FIGURE 10: Variation of the dimensions of the zones characterizing the behavior of the panel.
TABLE 1: Characteristics of the literature panels.

\begin{tabular}{lcccccc}
\hline Ref. $B(\mathrm{~mm})$ & $H(\mathrm{~mm})$ & $t(\mathrm{~mm})$ & $E_{m}(\mathrm{MPa})$ & $f_{m k}(\mathrm{MPa})$ & $N(\mathrm{kN})$ \\
\hline \multicolumn{7}{c}{ Unstrengthened panels } \\
{$[29]$} & 1250 & 1820 & 500 & 1118 & 6.0 & 343 \\
{$[30]$} & 1200 & 2400 & 500 & 726 & 4.5 & 311 \\
{$[29]$} & 1250 & 1850 & 500 & 1290 & 3.69 & 358 \\
{$[31]$} & 980 & 980 & 290 & 4880 & 3.4 & 242 \\
{$[32]$} & 1000 & 2000 & 250 & 1910 & 6.2 & 150 \\
{$[29]$} & 1250 & 1830 & 500 & 1125 & 6.0 & 355 \\
\hline \multicolumn{7}{c}{ FRP-strengthened panel } \\
{$[27]$} & 1480 & 1570 & 530 & 700 \\
\hline \multicolumn{7}{c}{}
\end{tabular}

panels (a), (c), and (f) which are characterized by a maximum height $H_{1}^{*}$ of the plastic zone less than $5 \%$ of the whole height of the panel and by a maximum base of the plastic zone less than $20 \%$ of its length $B$.

For the other panels (b) and (d), although the height $H_{1}^{*}$ of the plastic zone is less than $5 \%$ of the height of the panel, a greater portion of the base, about $30 \%$ of the base dimension, characterized the plastic zone.

In Figure 10 the curves representing the variation of the height of the different zones characterizing the behavior of panel (b) and panel (e) are reported: zone 1 with height equal to $H_{1}^{*}$, where $\varepsilon_{\max }>\varepsilon_{y}$; zone 2 with height equal to $H_{2}^{*}$, where $\varepsilon_{\max }<\varepsilon_{y}$, and only a portion of the section is in compression; zone 3 with height equal to $H_{3}^{*}$, where $\varepsilon_{\max }<\varepsilon_{y}$, and the whole section is in compression. In the figure the height $H_{i}^{*}$ is normalized with respect to the height $H$ of the panel and is plotted as a function of the position of the neutral axis at the base section.

The plots of Figure 10 clearly show the process of formation of the various zones characterizing the behavior of the panels when the external force $V$ increases. It is interesting to observe that in both cases $H_{2}^{*}=H_{3}^{*}$ when the neutral axis is located at the center of the section $(x / B=0.5)$, and the maximum value of the height $H_{1}^{*}$ of the panel (b) is about $0.05 H$ (i.e., $120 \mathrm{~mm}$ ) and about $0.1 H$ (i.e., $98 \mathrm{~mm}$ ) for panel (e). The different amplitudes of the plastic zone affects the global response of the panels (Figure 8), where a greater plastic deformation for the panel (e) is evident.

3.2. FRP-Strengthened Panels. The comparison between the experimental and the numerical capacity curves deduced for the strengthened panel experimentally examined in [27] is shown in Figure 11. Also in this case the developed model shows a good reliability in reproducing the global response of the panel. Indeed, the numerical curve well approximates the prepeak behavior and provides a good estimation of the peak load. Nevertheless, a significant degradation characterizing the pre-peak experimental behavior of the panel probably due to the gradual detachment of the strips, which is not accounted by the proposed model is evident. Moreover, differently from the unstrengthened panels, the FRP-strengthened panel shows a significant softening in the prepeak phase which emphasizes a fragile response. 


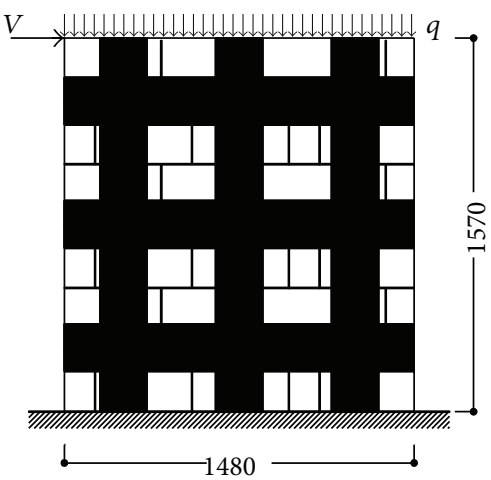

(a)

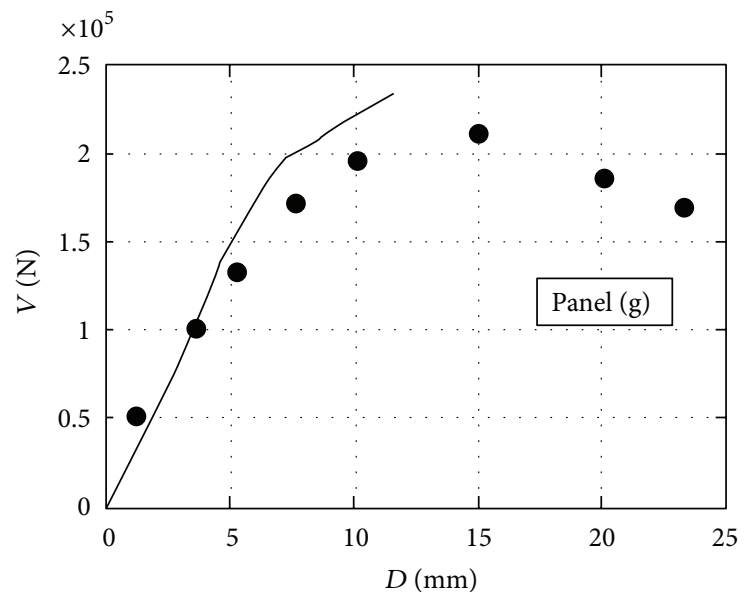

(b)

FIGURE 11: (a) Dimensions and strips arrangement of the considered FRP-strengthened panel [27]. (b) Comparison between numerical and experimental capacity curves of the FRP-strengthened panel.

\section{Conclusions}

In this paper a simple approach for evaluating the nonlinear response of unstrengthened and FRP-strengthened masonry panels subjected to in-plane vertical and lateral loads has been presented. The model belongs to the equivalent frame approach and consists of schematizing the panel as an assemblage of frame elements with flexure and shear deformability. The geometrical and mechanical properties of the elements are derived on the basis of the different stress-strain states characterizing the sectional behaviour.

The reliability of the proposed model is analysed by considering some experimental cases deduced from the literature. The comparison in terms of the capacity curve obtained by the numerical and the experimental studies has provided a satisfactory agreement especially for the prediction of the maximum load sustained by the panels and, in most of the cases, in terms of the ultimate displacement. However, for some of the analysed unstrengthened panels and for the FRP-strengthened panel, the numerical values of the ultimate displacement were less than the experimental values. These results, certainly due to the simplified hypothesis assumed for the masonry and FRP and, in particular, for their interaction mechanism, have evidenced the restrictions of the proposed model and could constitute the basis from which further development of the model itself is proposed.

The model, as proposed herein and being based only on few parameters obtained by standard experimental tests on masonry and FRP, aims at providing a simple tool to be used in the phase of assessment of masonry structures and in the preliminary design of the FRP-strengthening systems. Moreover the model could be applied also to the case of building facades because it provides the capacity curves of each wall bay constituting the facades.

\section{Symbols}

$N$ : Vertical load applied at the top of the panel along its central axis

$V$ : $\quad$ Horizontal load applied at the top of the panel

D: $\quad$ Horizontal displacement at the top of the panel

$B: \quad$ Width of the panel

$t$ : Thickness of the panel

$H$ : Height of the panel

$d_{1}$ : $\quad$ Distance of the left FRP sheet from the

$d_{2}$ : $\quad$ Distance of the right FRP sheet from the pistance of

$A_{f 1}, A_{f 2}: \quad$ Cross-section areas of the FRP strips

$H_{i}(i=1, \ldots, 4)$ : Height of the panel's portion with sections not fully compressed

$H_{i}^{*}(i=1, \ldots, 3)$ : Height of the homogenous zones of the panel

$E_{m}: \quad \quad$ Young's modulus of masonry

$G_{m}$ : $\quad$ Shear modulus of masonry

$f_{m k}: \quad$ Strength of masonry

$\varepsilon_{y}$ : $\quad$ Elastic limit strain of masonry

$\varepsilon_{u}: \quad \quad \quad$ Ultimate strain of masonry

$\varepsilon_{\max }: \quad$ Maximum strain of masonry in compression

$\varepsilon_{\min }: \quad$ Minimum strain of masonry in compression

$\varepsilon_{f u}: \quad \quad \quad$ Ultimate strain of FRP

$\varepsilon_{f 1}$ : $\quad$ Strain of the left FRP sheet at the base section

$\varepsilon_{f 2}$ : $\quad$ Strain of the right FRP sheet at the base section

$\varepsilon_{f 1,3}: \quad$ Strain of the left FRP sheet at the section located at $\mathrm{H}_{3}$ 


\begin{tabular}{|c|c|}
\hline $1,4:$ & ection \\
\hline & of the section \\
\hline & $\begin{array}{l}\text { Neutral axis of the section when } \varepsilon_{\max }= \\
\varepsilon_{y}\end{array}$ \\
\hline & \\
\hline & Stiffness matrix of the single element \\
\hline & Stiffness matrix of the panel \\
\hline & $\begin{array}{l}\text { Average value of the cross-section area of } \\
\text { the resisting sections located at the ends } \\
\text { of the element }\end{array}$ \\
\hline & $\begin{array}{l}\text { Average value of the moment of inertia } \\
\text { of the resisting sections }\end{array}$ \\
\hline & actor of the resisting section. \\
\hline
\end{tabular}

\section{References}

[1] E. Grande and A. Romano, "Experimental investigation and numerical analysis of tuff-brick listed masonry panels," Materials and Structures, vol. 46, no. 1-2, pp. 63-75, 2013.

[2] L. Decanini, A. de Sortis, A. Goretti, R. Langenbach, F. Mollaioli, and A. Rasulo, "Performance of masonry buildings during the 2002 Molise, Italy, earthquake," Earthquake Spectra, vol. 20, supplement 1, pp. S191-S220, 2004.

[3] D. F. D’Ayala and S. Paganoni, "Assessment and analysis of damage in L'Aquila historic city centre after 6th April 2009," Bulletin of Earthquake Engineering, vol. 9, no. 1, pp. 81-104, 2011.

[4] A. Khalifa, W. J. Gold, A. Nanni, and M. I. Abdel Aziz, "Contribution of externally bonded FRP to shear capacity of RC flexural members," Journal of Composites for Construction, vol. 2, no. 4, pp. 195-202, 1998.

[5] E. Grande, M. Imbimbo, and A. Rasulo, "Effect of transverse steel on the response of RC beams strengthened in shear by FRP: experimental study," Journal of Composites for Construction, vol. 13, no. 5, pp. 405-414, 2009.

[6] T. C. Triantafillou, "Strengthening of masonry structures using epoxy-bonded FRP laminates," Journal of Composites for Construction, vol. 2, no. 2, pp. 96-104, 1998.

[7] G. Marcari, G. Manfredi, A. Prota, and M. Pecce, "In-plane shear performance of masonry panels strengthened with FRP," Composites B, vol. 38, no. 7-8, pp. 887-901, 2007.

[8] K. M. C. Konthesingha, M. J. Masia, R. B. Petersen, N. Mojsilovic, G. Simundic, and A. W. Page, "Static cyclic inplane shear response of damaged masonry walls retrofitted with NSM FRP strips-an experimental evaluation," Engineering Structures, vol. 50, pp. 126-136, 2013.

[9] I. Cancelliere, M. Imbimbo, and E. Sacco, "Experimental tests and numerical modeling of reinforced masonry arches," Engineering Structures, vol. 32, no. 3, pp. 776-792, 2010.

[10] E. Grande, M. Imbimbo, and E. Sacco, "Bond behaviour of CFRP laminates glued on clay bricks: experimental and numerical study," Composites B, vol. 42, no. 2, pp. 330-340, 2011.

[11] E. Grande, M. Imbimbo, and E. Sacco, "Bond behavior of historical clay bricks strengthened with Steel Reinforced Polymers (SRP)," Materials, vol. 4, no. 3, pp. 585-600, 2011.

[12] M. R. Valluzzi, D. V. Oliveira, A. Caratelli et al., "Round Robin Test for composite-to-brick shear bond characterization," Materials and Structures, vol. 45, no. 12, pp. 1761-1791, 2012.

[13] M. Panizza, E. Garbin, M. R. Valluzzi, and C. Modena, "Bond behaviour of CFRP and GFRP laminates on brick masonry," in Proceedings of the 6th International Conference on Structural Analysis of Historic Construction: Preserving Safety and Significance (SAHC '08), D. D'Ayala and E. Fodde, Eds., pp. 763-770, Bath, UK, July 2008.

[14] D. V. Oliveira, I. Basilio, and P. B. Loureço, "Experimental bond behavior of FRP sheets glued on brick masonry," Journal of Composites for Construction, vol. 15, no. 1, pp. 32-41, 2011.

[15] E. Grande, M. Imbimbo, and E. Sacco, "Simple model for bond behavior of masonry elements strengthened with FRP," Journal of Composites for Construction, vol. 15, no. 3, pp. 354-363, 2011.

[16] E. Grande, M. Imbimbo, and E. Sacco, "A beam finite element for nonlinear analysis of masonry elements with or without fiber-reinforced plastic (FRP) reinforcements," International Journal of Architectural Heritage, vol. 5, no. 6, pp. 693-716, 2011.

[17] E. Grande, M. Imbimbo, and E. Sacco, "Finite element analysis of masonry panels strengthened with FRPs," Composites $B$, vol. 45, no. 1, pp. 1296-1309, 2013.

[18] G. Milani, K. Beyer, and A. Dazio, "Upper bound limit analysis of meso-mechanical spandrel models for the pushover analysis of 2D masonry frames," Engineering Structures, vol. 31, no. 11, pp. 2696-2710, 2009.

[19] A. Cundari and G. Milani, "Homogenized and heterogeneous limit analysis model for the pushover analysis of ancient masonry walls with irregular texture," International Journal of Architectural Heritage, vol. 7, no. 3, pp. 303-338, 2013.

[20] E. Grande, M. Imbimbo, and E. Sacco, "Modeling and numerical analysis of the bond behavior of masonry elements strengthened with SRP/SRG," Composites B, vol. 55, pp. 128-138, 2013.

[21] C. Maruccio, P. B. Lourenço, and D. V. Oliveira, "Development of a constitutive model for the masonry-FRP interface behaviour," in Proceedings of the 8th World Congress on Computational Mechanics, Venice, Italy, 2008.

[22] E. Grande, M. Imbimbo, and E. Sacco, "Finite element analysis of masonry panels strengthened with FRPs," Composites B, vol. 45, pp. 1296-1309, 2013.

[23] E. Grande, G. Milani, and E. Sacco, "Modelling and analysis of FRP-strengthened masonry panels," Engineering Structures, vol. 30, no. 7, pp. 1842-1860, 2008.

[24] G. Milani, P. B. Lourenço, and A. Tralli, "Homogenised limit analysis of masonry walls-part I: failure surfaces," Computers and Structures, vol. 84, no. 3-4, pp. 166-180, 2006.

[25] A. Caporale, L. Feo, and R. Luciano, "Limit analysis of FRP strengthened masonry arches via nonlinear and linear programming," Composites B, vol. 43, no. 2, pp. 439-446, 2012.

[26] G. Magenes and A. della Fontana, "Simplified non-linear seismic analysis of masonry buildings," Proceedings of the British Masonry Society, vol. 8, pp. 190-195, 1998.

[27] G. Marcari, Il rinforzo sismico di murature di tufo con materiali fibrorinforzati [Ph.D. thesis], University of Naples, 2005.

[28] MathWorks, Inc., Matlab Reference Manual, Version 6.5, MathWorks, Inc., Natick, Mass, USA, 2002.

[29] L. Fantoni, Rapporto Sulle Prove della Capacità Portante di Murature in Pietrame Iniettate, CRAD: Centro di Ricerca Applicata e Documentazione, Udine, Italy, 1981.

[30] G. Giambanco, S. Rizzo, and R. Spallino, Il Modello di Interfaccia a Doppia Asperità per l'analisi delle Strutture Discontinue, Atti del Convegno Nazionale: La Meccanica delle Murature tra Teoria e Progetto, Messina, Italy, 1996. 
[31] A. Giuffrè and A. Grimaldi, Studi Italiani Sulla Meccanica delle Murature, Atti del Convegno: Stato dell'arte in Italia sulla Meccanica delle Murature, Roma, Italy, 1985.

[32] A. Callerio, Comportamento sismico delle murature ne-gli edifici monumentali: un metodo di analisi basato sulla meccanica del danneggiamento [Doctoral dissertation], University of Naples, 1998. 

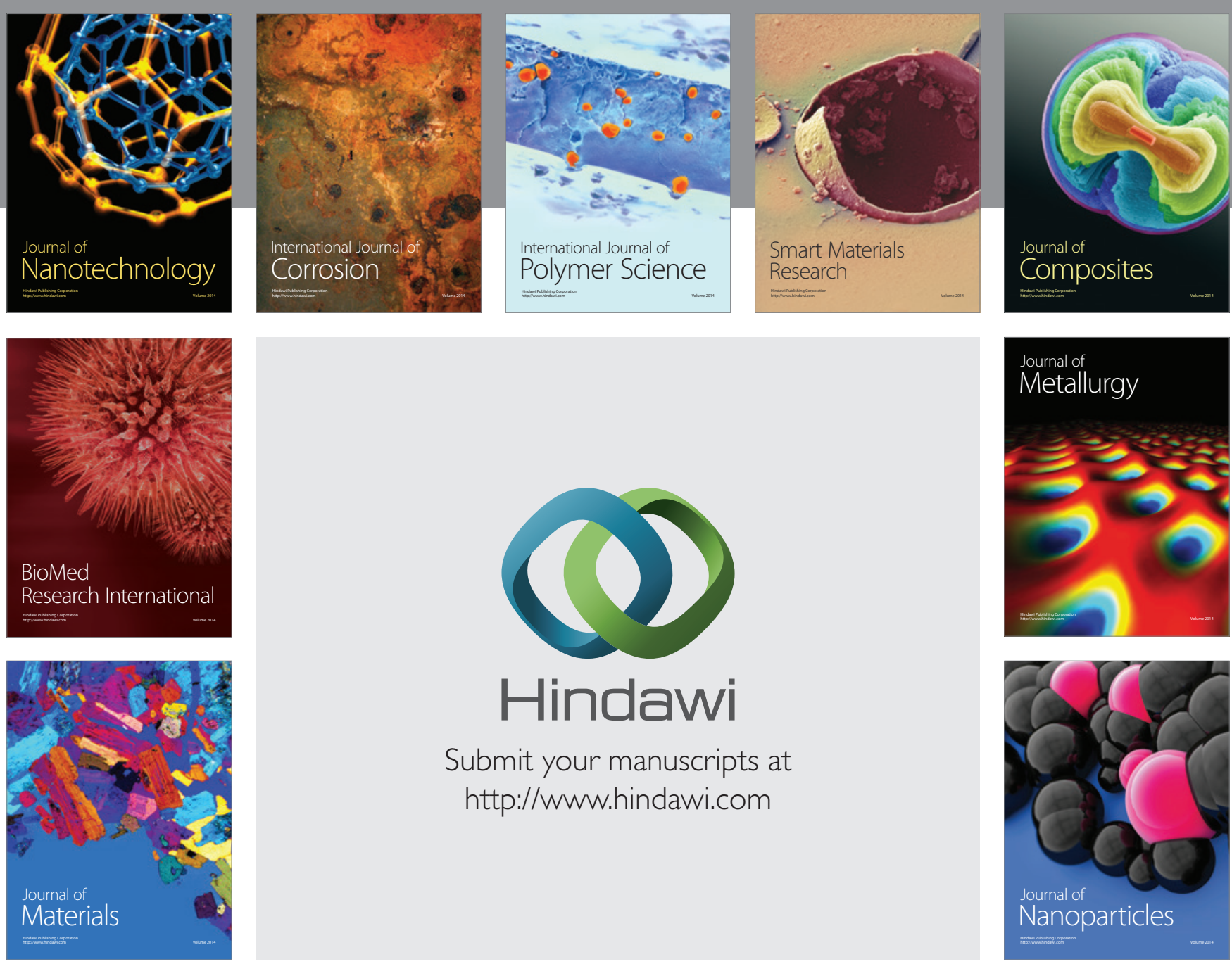

Submit your manuscripts at http://www.hindawi.com
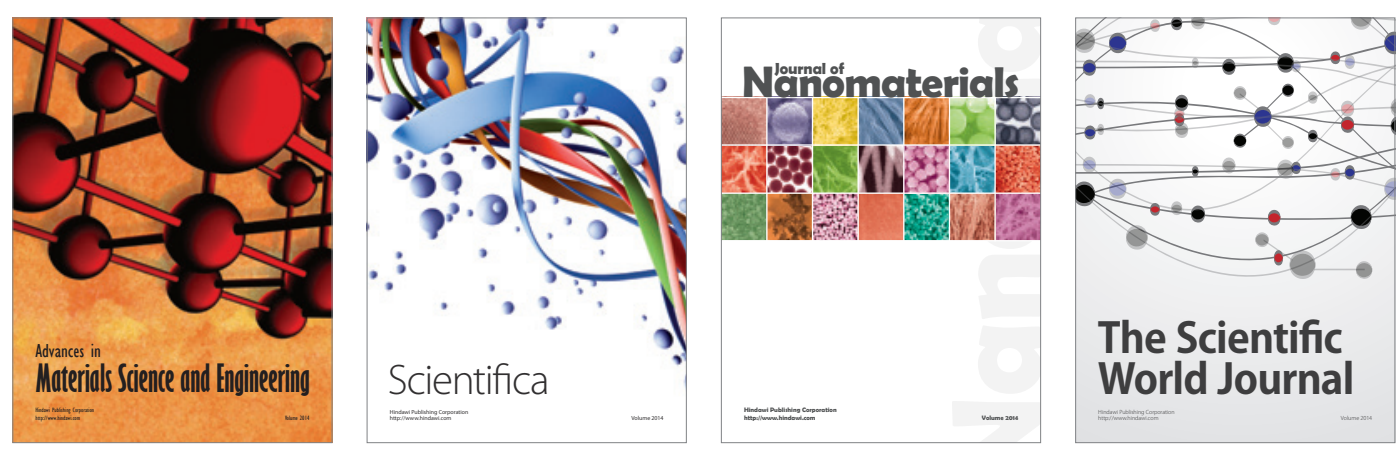

\section{The Scientific World Journal}
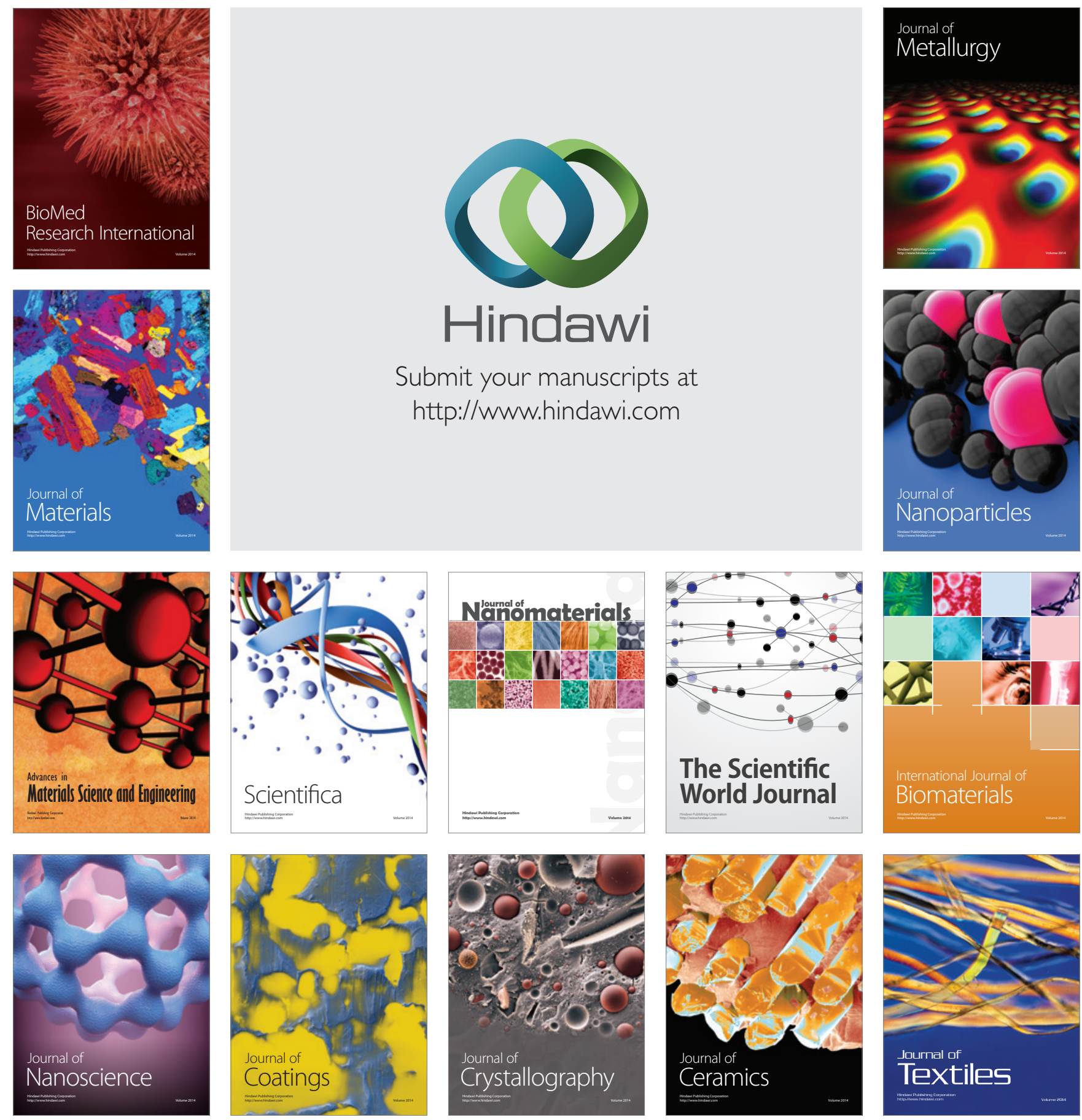